\title{
Endocannabinoid System Participates in Neuron-Glial Networks Adaptation to Modeled Ischemia Factors in vitro
}

DOI: $10.17691 / \mathrm{stm} 2017.9 .4 .08$

Received May 22, 2017

E.V. Mitroshina, PhD, Associate Professor, Department of Neurotechnologies, Institute of Biology

and Biomedicine; Senior Researcher, Laboratory for Neuroprotection Methods Development,

Center for Translational Technologies'; Senior Researcher, Molecular Cellular Technologies Department, Central Scientific Research Laboratory;

T.A. Mishchenko, PhD, Senior Researcher, Laboratory for Neuroprotection Methods Development, Center for Translational Technologies'; Senior Researcher, Molecular Cellular Technologies Department, Central Scientific Research Laboratory2;

N.V. Voronova, MSc, Department of Neurotechnologies, Institute of Biology and Biomedicine';

R.S. Yarkov, MSc, Department of Neurotechnologies, Institute of Biology and Biomedicine';

D.S. Asyutin, MD, PhD, Researcher, Department of Spinal Neurosurgery and Surgery of Peripheral Nerves;

M.A. Mishchenko, PhD, Senior Researcher, Department of Theory of Oscillations and Automatic Control';

M.V. Vedunova, DSc, Senior Researcher, Institute of Biology and Biomedicine;

Director of Institute of Biology and Biomedicine ${ }^{1}$

${ }^{1}$ Lobachevsky State University of Nizhni Novgorod, 23 Prospekt Gagarina, Nizhny Novgorod, 603950,

Russian Federation;

${ }^{2}$ Nizhny Novgorod State Medical Academy, 10/1 Minin and Pozharsky Square, Nizhny Novgorod, 603005,

Russian Federation;

${ }^{3}$ N.N. Burdenko National Scientific and Practical Center for Neurosurgery of the Ministry of Healthcare of the Russian Federation, 16, 4th Tverskaya-Yamskaya St., Moscow, 125047, Russian Federation

The aim of the study was to evaluate the role of a cannabinoid receptor agonist and blockers of key enzymes of endocannabinoid biodegradation in the adaptation of neuron-glial networks to ischemia factors influence.

Materials and Methods. Dissociated hippocampal cells obtained from C57BL/6 murine embryos on the $18^{\text {th }}$ day of gestation were cultivated as primary cultures. Two major factors of ischemia - hypoxia and glucose deprivation - were modeled on day 14 of culture development in vitro. Synthetic endocannabinoid N-arachidonoyl dopamine (NADA) at concentration of $10 \mu \mathrm{M}$, irreversible inhibitor of

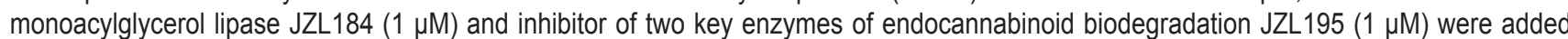
into the culture medium at the beginning of ischemia factors modeling or immediately after it. The cell viability was assessed on days 1,3 , and 7 after the influence of ischemia factors. On day 7 , the spontaneous calcium activity in primary hippocampal cells was analyzed using the multicellular functional calcium imaging. To reveal the molecular neuroprotective mechanisms of the tested compounds, expression of mRNA CB ${ }_{1 \mathrm{R}}$ receptor and mRNA hypoxia-inducible factor HIF-1a were measured using fluorescent mRNA detection probes (Smart Flare Merck, Germany).

Results. Application of NADA (the agonist of the cannabinoid type 1 and 2 receptors) or JZL195 (the MAGL/FAAH enzymes blocker) into the culture medium has been found to have a neuroprotective effect manifesting itself in a consistent cell death decrease compared with the control cultures. In addition, activation of the endocannabinoid system partially neutralizes the changes induced by hypoxia and glucose deprivation in vitro: the spontaneous calcium activity was detected in a greater number of cells (vs the control group), and the duration and frequency of calcium oscillations were partially normalized.

It was also found that NADA application during hypoxia significantly increased the type 1 cannabinoid receptors expression. When NADA and JZL195 were added the expression level of mRNA HIF-1a factor did not differ from that of the intact cultures.

Conclusion. The synthetic endocannabinoid NADA and the enzyme blocker JZL195 have a pronounced neuroprotective effect on the

For contacts: Elena V. Mitroshina, e-mail: helenmitroshina@gmail.com 
modeled ischemia factors consisting in the increase of neuronal cell viability and a good functional calcium activity of primary hippocampal cultures in a long-term period after injury.

Key words: endocannabinoid system; N-arachidonoyl dopamine; NADA; JZL195; JZL184; brain ischemia; brain hypoxia; primary cultures of hippocampal cells; neuroprotection.

One of the promising areas of modern neuroscience is the search of compounds with a neuroprotective potential, capable of supporting the activity of brain neural networks, as well as the cognitive and mnestic functions after an ischemic injury, and thus improving the adaptive resources of the human organism.

Over the past two decades, evidence has emerged that the endogenous regulatory systems play an important role in ensuring the resistance of nervous cells to various damaging factors [1-4]. Of great interest is the neuroprotective potential of substances able to modulate the endocannabinoid system (ECS). This system includes the endogenous ligands of cannabinoid receptors as well as the receptors themselves; those are located on the cell membrane and represented primarily by cannabinoid receptors types 1 and $2\left(\mathrm{CB}_{1 \mathrm{R}}\right.$ and $\left.\mathrm{CB}_{2 \mathrm{R}}\right)$. The enzymes participating in the biosynthesis and inactivation of endogenous ligands are also considered as a part of the ECS $[5,6]$.

The ECS is a regulating system that modulates various physiological processes in the organism. One of its key functions is the regulation of synaptic transmission, as well as the regulation of eating and emotional behavior, sensitivity to pain, etc. The ECS plays an important role in other functions, regulating, for example, the activity of the immune system. The cannabinoid receptors, ligands and the enzymes of endocannabinoid biodegradation - monoacylglycerol lipase (MAGL) and fatty acid amide hydrolase (FAAH) - were found in all parts of the nervous system [7].

The neuroprotective effects of ECS components have been demonstrated in various models of diseases and brain and the spinal cord injuries, as shown for ligands of the cannabinoid receptors [4, 6, 8-14], for inhibitors of the endocannabinoids inactivation, and for allosteric modulators of the ECS enzymes [15-20]. Over the past decade, the role of ECS in the homeostatic mechanisms, protecting the nervous system against injuries and other stress factors has been confirmed [4, 6]. In neurodegenerative diseases, cannabinoids reduce the damage to nerve tissue by providing antioxidant, antiinflammatory and anti-toxic protection. This combined effect on a variety pathogenetic molecular cascades makes the ECS superior among others neuroprotective compounds, which act only on a single mechanism of the ischemic damage, for example, the NMDA receptor blockers.

It is obvious that the pathogenesis of most neurodegenerative disorders and other CNS diseases is the combination of various pathogenetic cascades, therefore a reliable strategy for preserving the functional activity of neurons requires a complex of protective effects on all or most of these molecular cascades. Various types of cannabinoid receptors present in all key cells of the nervous system (neurons, astrocytes, resting and reactive microglia, oligodendrocytes and progenitor cells of oligodendrocytes, as well as neuronal precursors) in all brain structures [6, 21]. Therefore, by using ECS it is possible to simultaneously reduce the excitotoxicity by activating cannabinoid receptors type 1 located on neurons $\left(\mathrm{CB}_{1 \mathrm{R}}\right)$, to reduce the negative effects of reactive microgliosis by acting through the microglial cannabinoid receptors type $2\left(\mathrm{CB}_{2 R}\right)$, and to enhance the trophic and metabolic support of neurons affected by ischemia, realizing through the astrocytic receptors $C_{1 R}$ or $\mathrm{CB}_{2 \mathrm{R}}$ (Figure 1).

It should be noted that the cannabinoid effects can be implemented through the mechanisms not associated with cannabinoid receptors or enzymes but activating transcription factors (eg, Nrf-2 and NF$\mathrm{KB})$ or nuclear receptors activated by the peroxisome proliferator-activated receptors (PPAR) for limitation of oxidative stress and inflammatory reactions [6, 22]. Currently, the most elaborated way to activate ECS is the introduction of synthetic analogues of endogenous cannabinoids. Another method of activating ECS is the use of agents inhibiting the enzymes of endocannabinoid biodegradation (MAGL and FAAH) and increasing the concentration of endogenously synthesized cannabinoids in tissues. This method albeit promising is not sufficiently explored. Carloni et al. [16] showed that the use of the MAGL inhibitor reduces the apoptotic and necrotic death of brain cells in experimental animals with perinatal hypoxia. The neuroprotective effect of the MAGL inhibitor JZL184 was found in the model of Alzheimer's disease in APdE9 mice [15]. The protective effect was demonstrated with the FAAH blockers in the model of Parkinson's disease [18].

Thus, the research into the ways of activating the ECS using optimal approaches that can protect nervous cells from biological damage, including the ischemic one, is highly relevant.

The aim of the study was to evaluate the role of a cannabinoid receptor agonist and blockers of key enzymes of endocannabinoid biodegradation in the adaptation of neuronal-glial networks to ischemia factors influence. 


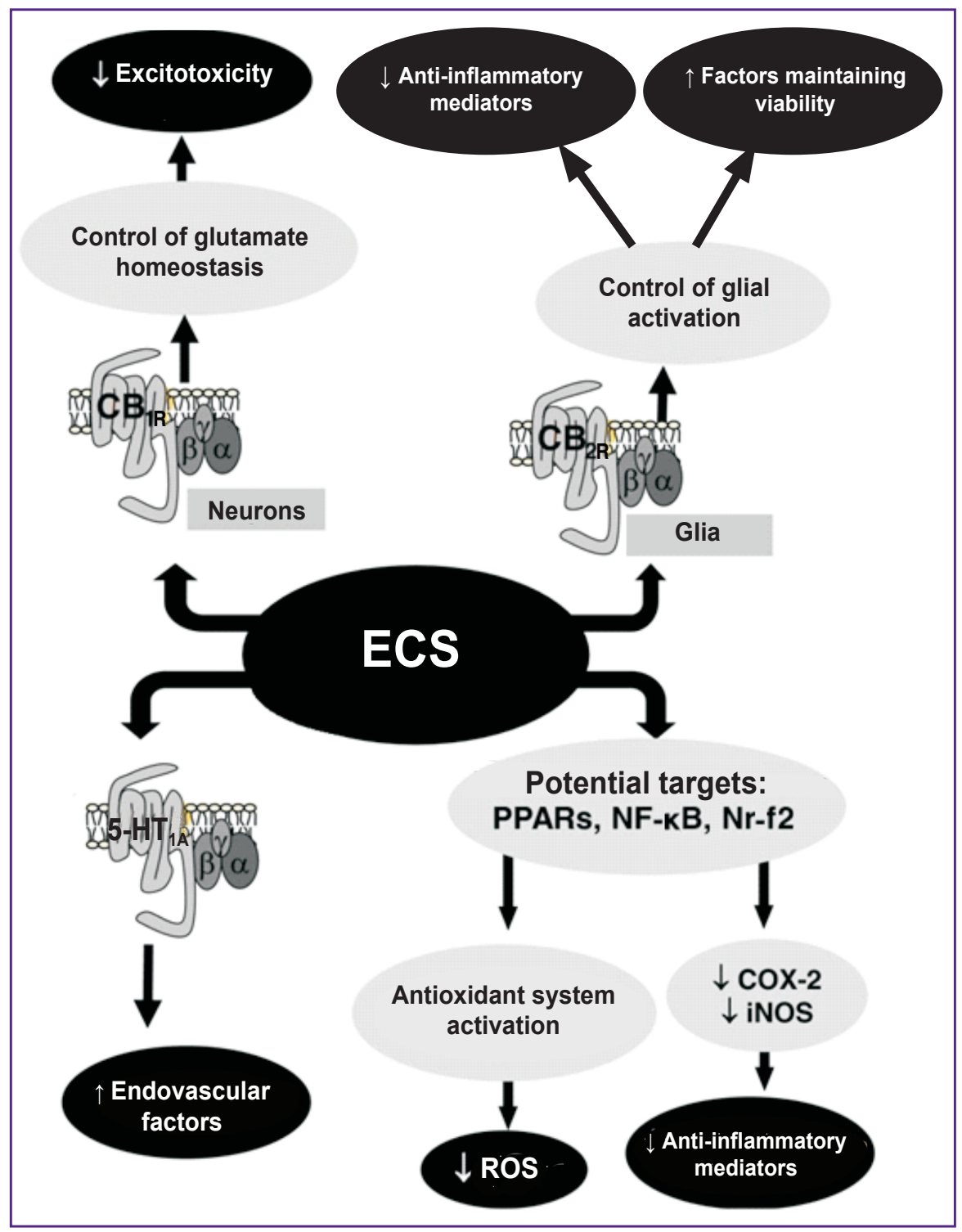

Figure 1. Modified scheme of molecular and cellular mechanisms of the neuroprotective properties of endocannabinoids [2]:

$\mathrm{CB}_{1 \mathrm{R}}$-cannabinoid receptor type 1; $\mathrm{CB}_{2 \mathrm{R}}$ - cannabinoid receptor type 2; PPARs - receptors activated by peroxisome proliferator; NF$\mathrm{KB}$ - transcription factor (nuclear factor kappa-light-chain-enhancer of activated B cells); Nrf-2 transcription factor; ROS - reactive oxygen species; COX-2 cyclooxygenase 2; iNOS - inducible NO-synthase; $5-\mathrm{HT}_{1 \mathrm{~A}}-$ subtype of serotonin receptors of the $5-\mathrm{HT}_{1}$ subfamily; $\alpha, \beta, y-$ subunits of the G-protein coupled with receptor; ECS - endocannabinoid system

\section{Materials and Methods}

Primary hippocampal cultures. Dissociated hippocampal cells obtained from C57BL/6 murine embryos on day 18 of gestation were used for the primary cultures. The basic rules for the maintenance and care of experimental animals were in accordance with the standards specified in Order No.267 of the Ministry of Healthcare of the Russian Federation of June 19, 2003 "On Approval of the Rules of Laboratory Practice in the Russian Federation". Enzymatic dissociation of embryonic hippocampal cells was carried out by the treatment with $0.25 \%$ trypsin solution (Gibco, USA). Primary cell cultures were maintained in the Neurobasal medium (Thermo Fisher Scientific, USA) supplemented with the B27 bioactive additive (Thermo Fisher Scientific, USA), L-glutamine (Thermo Fisher Scientific, USA), and fetal bovine serum (PanEko, Russia) for 21 days on coverslips pre-treated with polyethyleneimine (Sigma-Aldrich, Germany) to increase cell adhesion to the surface, as described in the previously developed protocol $[23,24]$. The initial density of cells in culture was 9,000 cells $/ \mathrm{mm}^{2}$. The cultures were cultured in a cell culture incubator (MCO-18AIC, Sanyo, Japan) at $35.5^{\circ} \mathrm{C}$ and $5 \% \mathrm{CO}_{2}$.

Hypoxia model. The experiment was conducted on day 14 of culture development by replacing the regular medium with a low oxygen medium for $10 \mathrm{~min}$. Oxygen was removed by saturating the culture medium with argon. The experiment was carried out in a sealed chamber where the air was also replaced with argon. One of the tested compounds: the synthetic endocannabinoid, the $\mathrm{CB}_{1 \mathrm{R}}, \mathrm{CB}_{2 \mathrm{R}}$ and TRPV1 receptor agonist NADA (N-arachidonoyl dopamine) - $10 \mu \mathrm{M}$; the irreversible MAGL inhibitor JZL184 (4-nitrophenyl4-[bis(1, 3-benzodioxol-5-yl)(hydroxy)methyl]piperidine1-carboxylate) - $1 \mu \mathrm{M}$; the inhibitor of both key endocannabinoid biodegradation enzymes, FAAH and MAGL, JZL195 (4-nitrophenyl)4-[(3-phenoxyphenyl) 
methyl]piperazine-1-carboxylic acid) $-1 \mu \mathrm{M}$ was added into culture medium (either in hypoxic conditions and after reoxygenation) as shown in Figure 2.

Glucose deprivation model was performed on day 14 of culture development by replacing the standard culture medium with a medium that contained no glucose, lactate or pyruvate, for $2 \mathrm{~h}$. After this period, the medium was replaced with the regular one. The addition of the tested compounds was carried out in the same way as in the hypoxia model.

Evaluation of cell viability. The cell viability in the dissociated hippocampal culture was assessed on days 1, 3, and 7 after modeling hypoxia or glucose deprivation. The number of cell nuclei stained by propidium iodide (81845-25MG; Sigma, USA) reflected the number of dead cells, and the nuclei stained by bis-benzimide (14530-100MG; Sigma, USA) reported on the total cell count. Accordingly, the cell death rate was quantified as the ratio (\%) of the propidium iodide positive to the bisbenzimide positive cells [24].

Functional calcium imaging. To study the metabolic activity of cells in the primary hippocampal cultures, we used the method of calcium imaging that allows monitoring of cytoplasmic calcium, which reflects the functional architecture of neural networks. The primary hippocampal cells are characterized by a spontaneous periodic increase in the concentration of $\mathrm{Ca}^{2+}$ ions in the cytoplasm, which is due to the activation of ion channels on the postsynaptic membrane. After entering the cytoplasm, calcium readily binds to the cellular calciumbinding system. Such calcium activity can be studied using ion-sensitive fluorescent probes [25].

The specific calcium dye OregonGreen 488 BAPTA-1 AM (OGB1) (Thermo Fisher Scientific, USA) was used as a fluorescent probe. Staining was performed according to the standard protocol [26]. To monitor the fluorescence, a laser scanning microscope LSM 510 NLO (Carl Zeiss, Germany) was used. The temporal series of fluorescent images were recorded. The fluorescence of the OGB1 dye was excited by a 488-nm argon laser, and the signal was recorded using a filter with a band of 500-530 $\mathrm{nm}$. We analyzed changes in the fluorescence signal (arbitrary units) from the microscopic field where the selected cell was located. Detection and analysis of calcium oscillations were conducted using the original software package "Astroscanner" (the certificate of state registration of the computer program No.20114662670). We then operated with the function $F(t)$, i.e. the mean fluorescence intensity in the selected microscopic field over the time of observation. The following parameters were taken into account: the duration (s), the frequency (number of calcium events per minute), and the percentage of cells in the culture exhibited calcium activity [26].
Intravital mRNA detection. For the mRNA intravital detection, the RNA-detection probes SmartFlare (Merck, Germany) were used. This method allows measuring the level of mRNA expression in live and functioning cells. The mRNA detection probes are absorbed by living cells via natural endocytosis. These probes enter the cell and bind to the complementary target RNA sequences. After that, the fluorophore is released and can be detected by fluorescence microscopy [27]. The RNA probes were added into the culture medium after hypoxia modeling on day 14 of culture development in vitro.

To study the molecular mechanisms of the neuroprotective effects induced by the activation of the ECS we studied the expression of mRNA $C_{1 R}$ receptor and the hypoxia-inducible factor HIF-1a. To determine the level of nonspecific staining and the technical aspects of the RNA detection assay, we used the following controls: the negative control (Scramble) (Merck, Germany) - the RNA probe with no homology to any nucleotide sequences in biological cells - that allowed us to determine the background fluorescence caused by a nonspecific release of fluorescent strands; the positive control (Uptake) (Merck, Germany) — the RNA probe, which always fluoresces inside the cell and allows quantifying the RNA probes absorbed by the cell; the control for the housekeeping genes (Merck, Germany), it is a positive control for the detection of mRNA and is always active in cells (it detects the mRNA of the $18 \mathrm{~S}$ ribosome subunit). A confocal laser-scanning microscope (LSM 510; Carl Zeiss, Germany) was used to detect the fluorescence.

Statistical analysis. The obtained data are presented as the mean \pm standard error of the mean (SEM). The significance of the differences between the 
experimental groups was determined using the ANOVA package in SigmaPlot 11.0 (Systat Software Inc.). Differences were considered statistically significant at $p<0.05$.

Results. At the first stage of this study, the cell viability under the modeled ischemia factors was measured. It was found that both hypoxia and glucose deprivation caused a statistically significant (ANOVA, $p<0.05)$ increase in the number of dead cells in the culture on the first day after treatment. It was also found that the decrease in cell viability continued up to 7 days after exposure. On day 7 after the hypoxia modeling, the percentage of dead cells was 4.8 times higher compared to the intact cultures $(80.69 \pm 19.56$ vs $16.64 \pm 7.7 \%$, respectively). In the cultures subjected to temporary glucose deprivation, the number of dead cells

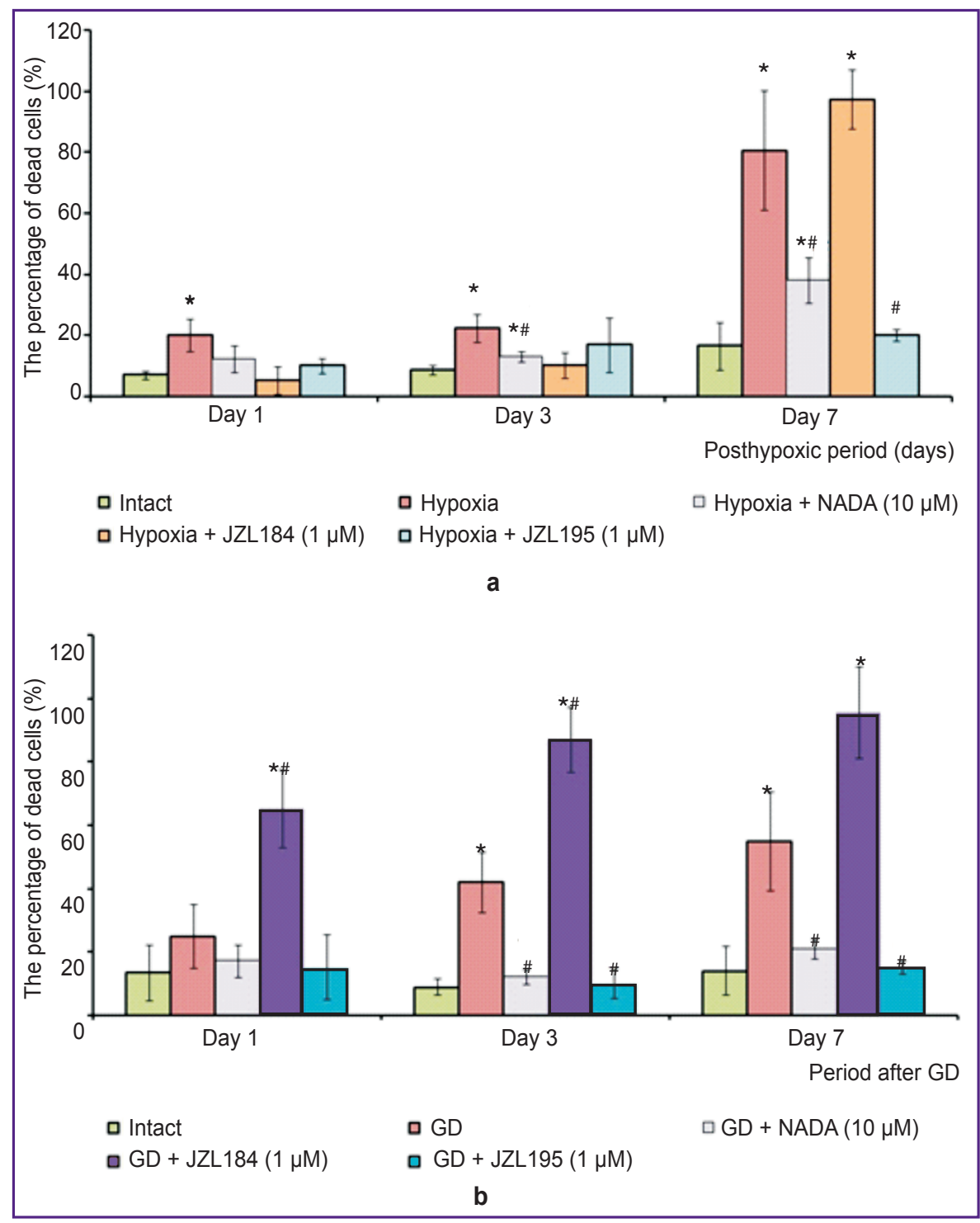

Figure 3. The percentage of dead cells in dissociated hippocampal cultures on days 1,3 , and 7 after ischemia modeling:

(a) hypoxia; (b) glucose deprivation (GD); the differences are statistically significant $(p<0.05)$ compared with * control, \# hypoxia or GD, respectively on day 7 was 3.9 times higher than in the intact cultures $(55.0 \pm 15.6$ vs $14.2 \pm 7.7 \%$ ) (Figure 3 ).

The addition of the synthetic endocannabinoid NADA $(10 \mu \mathrm{M})$ prevented the decrease in cell viability all over the observation period (on day 7 after the hypoxia, the percentage of dead cells was $38.4 \pm 7.4 \%$, and after the glucose deprivation $-21.6 \pm 3.1 \%$ ).

The endocannabinoid degradation blocker JZL195 $(1 \mu \mathrm{M})$ increased the cell viability in the ischemia factors models. In hypoxic states, the viability of the "Hypoxia + JZL195" cell cultures did not differ from the intact cultures; the "Hypoxia + JZL195" cell viability was significantly higher (ANOVA, $\mathrm{p}<0.05)$ compared to "Hypoxia" group $(20.1 \pm 2.0 \%)$. In the "Glucose deprivation + JZL195" group (on day 7 after the treatment), there was a slight viability decrease which was not statistically different from the intact group $(15.1 \pm 2.7 \%)$.

Interestingly, the use of the MAGL blocker JZL184 $(1 \mu \mathrm{M})$ in both the hypoxia and the glucose deprivation models adversely affected in cell viability (on day 7 after hypoxia, the addition of JZL184 resulted in $97.3 \pm 9.6 \%$ of dead cells, and with the glucose deprivation $-98.5 \pm 14.6 \%$ ).

In summary, the addition of the cannabinoid receptor (type 1 and type 2) agonist NADA and the enzyme blocker JZL195 causes a neuroprotective effect, which manifests in a significant decrease in the number of dead cells in comparison with control cultures subjected to ischemia factors (hypoxia and glucose deprivation). Moreover, in the hypoxia model, JZL195 showed a more pronounced neuroprotective effect in comparison with NADA. In contrast to the above substances, the blocker JZL184 did not confer protection and did not improve the cell viability. Therefore, NADA and JZL195 were selected for further studies.

At the next stage, we studied the effects of ECS on the ischemia-induced changes in the spontaneous calcium activity in the primary hippocampal cultures. As for today, there is no doubt that major functions of the nervous system - the processing and transmission of information, the consolidation of 
memory, the emotions and the behavioral reactions are not performed by individual neurons, but by entire neural networks; those are considered the minimal functional unit of the nervous system [28]. Changes in the functional activity of neural networks play a key role in the brain response to stress factors. Following the changes in the calcium concentration in cell allows analyzing the functional metabolic activity of both the neurons and the glial cells [26].

As part of our study, experiments with multicellular calcium imaging were performed. By using this method it is possible to investigate the metabolic activity of individual cells in the neural networks, which are formed in the primary hippocampal cultures. In the intact cultures, spontaneous calcium activity was observed on day 21 of cultures development. The frequency of calcium oscillations in the neural network was $2.2 \pm 0.2$ per minute, $91.1 \pm 3.5 \%$ of the cells showed calcium activity (Figure $4(a)$, (e)). On day 7 of the post-hypoxic period, a sharp decrease in the spontaneous calcium activity was registered: only $34.0 \pm 13.4 \%$ of cells showed the activity, whereas the frequency of calcium oscillations decreased up to $0.94 \pm 0.21$ oscillations per minute (ANOVA, $p<0.05$ ). The duration of calcium oscillations changed insignificantly.

The effect of endocannabinoid biodegradation enzymes blocking with JZL195 manifested in the preservation of spontaneous calcium activity. The activity was detected in $79.7 \pm 15.5 \%$ of cells (see Figure $4(e)$ ). The frequency of calcium oscillations in the presence of JZL195 decreased in 2.4 times as compared with the intact cultures and amounted to $0.9 \pm 0.3$ oscillations per minute. The duration of calcium oscillations almost doubled in comparison with the intact cultures $(12.8 \pm 1.7$ and $6.7 \pm 1.3 \mathrm{~s}$, respectively, $p<0.05$, ANOVA).

NADA also showed an anti-hypoxic effect. Spontaneous calcium activity in this experimental group was found in $86.8 \pm 7.7 \%$ of cells (see Figure 4 (e)).

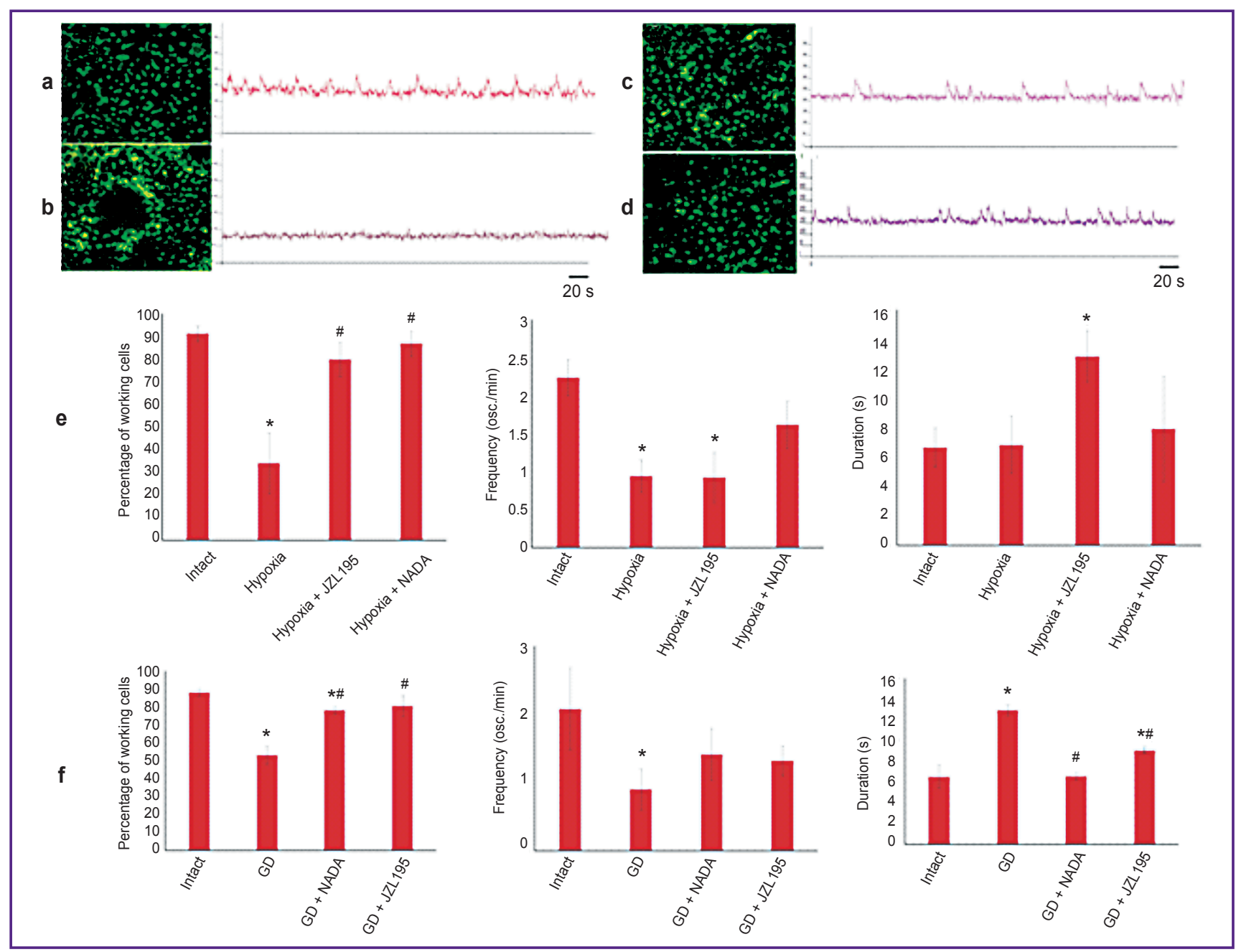

Figure 4. Representative recordings of calcium activity in primary hippocampal cultures:

(a) intact culture; (b) hypoxia; (c) hypoxia + JZL195; (d) hypoxia + NADA; (e), (f) the main parameters of spontaneous calcium activity on day 7 after hypoxia or glucose deprivation (GD), respectively; the differences are statistically significant $(p<0.05)$ compared with * control, \# hypoxia or GD, respectively 
The neuroprotective effect of NADA on the oscillation frequency was more pronounced than JZL195 effect (decrease in 1.4 times vs the intact group) and significantly different from the "Hypoxia" group. The duration of calcium oscillations in the NADA group insignificantly increased and amounted to $23.8 \pm 7.7 \mathrm{~s}$.

On day 7 after the glucose deprivation modeling, we found a significant decrease in spontaneous calcium activity: only $53.2 \pm 5.0 \%$ of cells showed the activity, and the frequency of calcium oscillations decreased in 2.2 times up to $0.9 \pm 0.04$ oscillations per minute (ANOVA, $\mathrm{p}<0.05)$. In contrast to hypoxia, glucose deprivation caused a significant (ANOVA, $p<0.05$ ) increase in the duration of calcium oscillations in 2 times (38.8 $\pm 1.5 \mathrm{~s})$ (Figure 4 (f)).

We found that both methods of ECS activation partially prevented the decrease in calcium activity caused by glucose deprivation. The neuroprotective

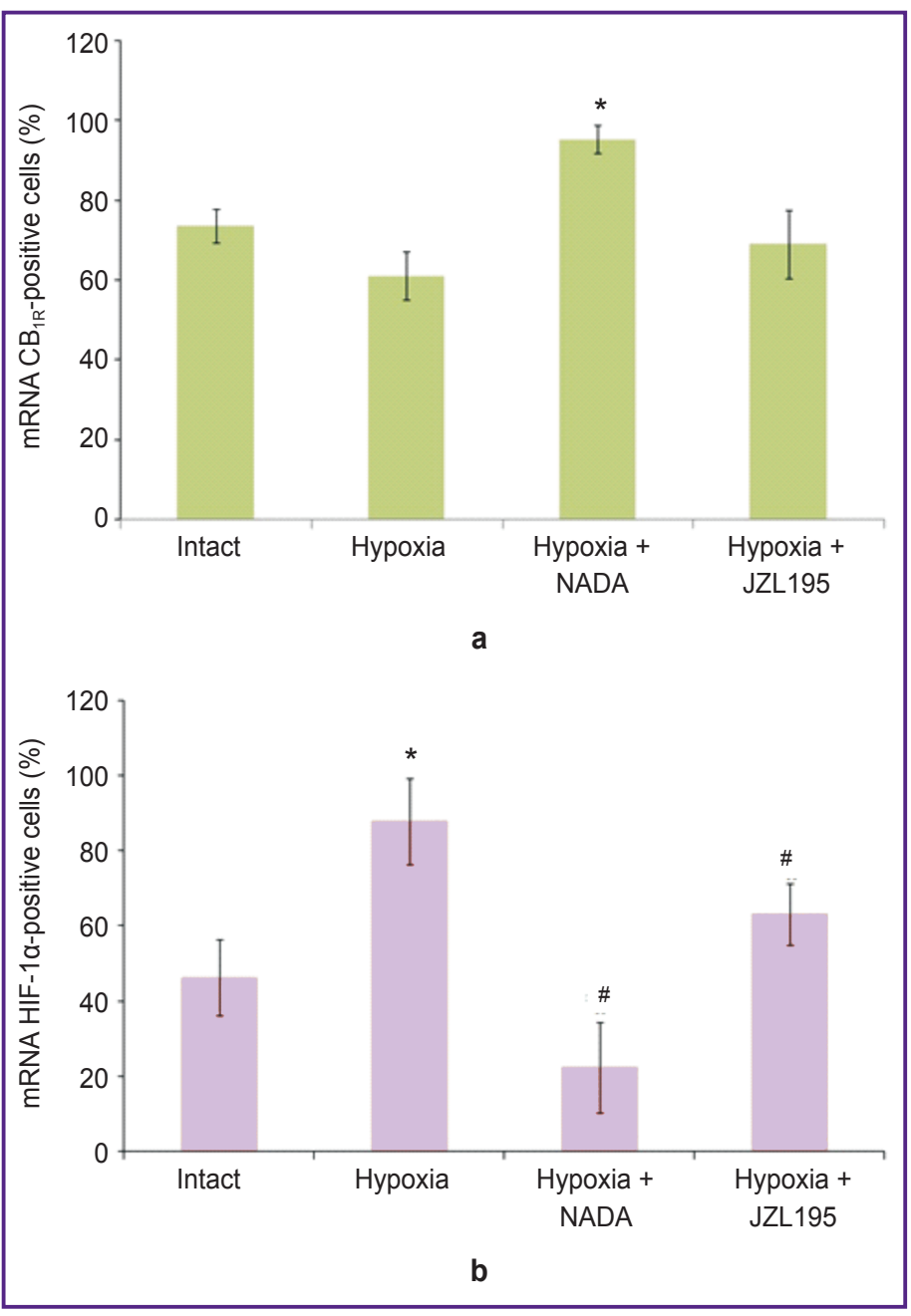

Figure 5. Investigation of possible molecular mechanisms of the endocannabinoid system neuroprotective action - mRNA detection on day 3 after hypoxia modeling in vitro:

(a) intravital expression of $\mathrm{mRNA} \mathrm{CB}_{1 \mathrm{R}}$; (b) intravital expression of mRNA HIF-1 $\alpha$; the differences are statistically significant $(p<0.05)$ compared with * control, \# hypoxia effect of JZL195 manifested in maintaining the number of active cells $(80.6 \pm 5.8 \%$ ) (see Figure $4(\mathrm{f})$ ), and in partially preserving the frequency and duration of calcium oscillations. In the background of JZL195 application the frequency of calcium oscillations in cells decreased in 1.6 times compared to intact cultures (1.3 \pm 0.2 oscillations per minute). The duration of calcium oscillations increased in 1.4 times in comparison with intact cultures $(9.1 \pm 0.3$ and $6.6 \pm 0.3 \mathrm{~s}$, respectively). In addition, NADA showed a neuroprotective effect. In its presence, $78.1 \pm 2.4 \%$ of cells exhibited the calcium activity (see Figure 4 (f)). The frequency of calcium oscillations with NADA was lower in 1.5 times than in the intact cultures $(1.4 \pm 0.4$ oscillations per minute). The duration of calcium oscillations was significantly lower as compared with the "Hypoxia" group and did not differ from intact cultures $(6.6 \pm 0.4 \mathrm{~s})$.

Thus, our study has shown that ECS plays an important role in maintaining the metabolic activity of cells in neural network in ischemia factors influence.

To understand the molecular mechanisms of the NADA and JZL195-induced neuroprotection, we followed the changes in the expression of mRNA $\mathrm{CB}_{1 \mathrm{R}}$ receptor on day 3 after hypoxia modeling. Intravital detection of mRNA $\mathrm{CB}_{1 \mathrm{R}}$ showed that in the primary hippocampal cultures, mRNA $\mathrm{CB}_{1 \mathrm{R}}$ is actively produced by both neuronal and glial cells. Hypoxia caused a slight decrease in the number of mRNA $\mathrm{CB}_{1 \mathrm{R}}$-positive cells (from $73.6 \pm 4.3$ to $61.1 \pm 6.0 \%)$. In the "Hypoxia + JZL195" group, the number of these cells was close to that in the intact cultures: $69.1 \pm 8.5 \%$ (Figure 5 (a)). In the "Hypoxia + NADA" group, the percentage of mRNA CB ${ }_{1 R}$-positive cells significantly increased to $95.2 \pm 3.5 \%$. Therefore, application of the synthetic endocannabinoid NADA significantly increased the expression of cannabinoid receptors type 1.

Over recent years, experimental evidence supporting the role of HIF-1a in the neuroprotective effect of ECS against the hypoxia-induced damage has accumulated. To follow this line of research, we studied the expression of mRNA HIF-1a in the presence of the tested compounds following the hypoxia modeling. We found that on day 3 after hypoxia, the expression of mRNA HIF-1 $1 \alpha$ increased in 1.9 times compared to the intact cultures (ANOVA, $p<0.05$ ): the proportion of mRNA HIF-1apositive cells in the intact group was $46.2 \pm 10.1 \%$, and in the "Hypoxia" group - 87.8 $\pm 11.5 \%$ (Figure 5 (b)). The use of NADA caused a 2 -fold decrease in the percentage of cells expressing mRNA HIF-1a $(22.3 \pm 12.1 \%$, ANOVA, $p<0.05)$. The use of the endocannabinoid biodegradation blocker resulted in a tendency to increasing mRNA HIF-1a expression $(63.2 \pm 8.2 \%)$, although this trend did not reach statistical significance.

Discussion. In the present study, we have found 
that activating the ECS with the synthetic cannabinoid analogue NADA or blocking the endocannabinoid biodegradation enzymes results in an anti-hypoxic and a neuroprotective effect on primary hippocampal cells in the modeled ischemia factors influence (hypoxia and glucose deprivation). In addition to the reduced number of dead cells, the ECS activation is able to partially neutralize the detrimental changes in spontaneous calcium activity manifesting in the maintaining of a high number of cells exhibited calcium activity, as well as in partial normalization of the duration and frequency of calcium oscillations. Among the two biologically active compounds, NADA had a higher neuroprotective effect than JZL195. Application of NADA allows preserving the number of cells exhibited calcium activity at initial level and also the frequency and duration of calcium oscillations, which are important for normal functioning of nervous cells.

Our results indicate that cannabinoid receptors type 1 play a key role in the ECS neuroprotection, which is consistent with previous reports [29-34]. Using the method of fluorescent RNA probes for intravital mRNA detection we found that NADA significantly increased the number of detectable mRNA $C_{1 R}$ positive cells. As suggested, the increased $C_{1 R}$ expression allows endocannabinoids to interfere with the cytotoxic cascades induced by hypoxia.

We also examined the possible role of hypoxiainduced factor HIF-1a in the neuroprotective action of ECS. This transcription factor controls the transport of oxygen to tissues and adapts the cell to oxygen starvation by regulating the expression of gene products involved in energy cellular metabolism, glucose transport, apoptosis, erythropoiesis, angiogenesis, and cell proliferation, thereby affecting the interaction not only between cells but also between the cell and the substrate [35]. HIF is a heterodimer that includes the constitutive subunit HIF- $\beta$ and the subunit HIF- $\alpha$; the latter has three isoforms, HIF-1 $1 \alpha, \mathrm{HIF}-2 \alpha$, and HIF-3a. Expression of HIF-1 $\alpha$ depends on the partial pressure of oxygen in the blood and increases with hypoxia [3638]. The role of HIF-1 $1 \alpha$ in hypoxia has been extensively studied, yet information on possible connection between ECS and HIF-1 $1 \alpha$ has become available just recently. The data of Soler-Torronteras et al. [39] indicate that $\mathrm{N}$-acyl dopamine increases the expression of HIF-1a by cells of primary neuronal cultures under normoxic conditions. The work of Abán et al. [40] showed that the hypoxia-induced increase of HIF-1a leads to a decrease in FAAH expression, and also decreases the viability of trophoblasts. These studies suggest that the change in HIF-1a production could be one of the possible molecular mechanisms of the endocannabinoids neuroprotective effect. Our study showed that hypoxia caused a significant increase in HIF-1 $1 \alpha$ expression, which confirms the previous data [37-39]. Activation of ECS by the tested substances preserves the level of mRNA HIF-1a expression close to the parameters of intact cultures.
Available data concerning the role of HIF-1a in brain adaptation to hypoxia are contradictory. Although a number of studies have shown that HIF-1a stimulates erythropoiesis and angiopoiesis, and thus increase the resistance to hypoxia [41-45], some studies indicate that HIF-1a plays a negative role in adapting the nervous cells to hypoxic conditions [38]. Some authors suggest that HIF-1 $\alpha$ is able to activate the proapoptotic p53 gene under conditions of hypoxia $[46,47]$ or craniocerebral trauma [48]. We believe that the preservation of HIF$1 \alpha$ expression at a stable level is one of the molecular mechanisms of the NADA neuroprotective action and helps prevent the apoptosis induction.

Conclusion. The synthetic cannabinoid analogue $\mathrm{N}$-arachidonoyl dopamine $(10 \mu \mathrm{M})$ and the cannabinoid biodegradation inhibitor JZL195 (1 $\mu \mathrm{M})$ have neuroprotective effects on primary hippocampal cultures subjected to ischemic factors including the maintaining the cell viability and preservation of spontaneous calcium activity.

Financial Support. This study was supported by the Russian Science Foundation for Basic Research (\#17-04-01128 a, 16-34-00301 mol_a), with the support of state projects "Provision scientific research" \#6.6379.2017/BP, 17.3335.2017/PP), Grant of the President of the Russian Federation MD-2634.2017.4 and Russian Science Foundation \#17-75-10149 in a part of mRNA expression studies.

Conflict of Interests. The authors declare no conflict of the interests mandatory to be reported.

\section{References}

1. Numakawa T. Possible protective action of neurotrophic factors and natural compounds against common neurodegenerative diseases. Neural Regen Res 2014; 9(16): 1506-1508, https://doi.org/10.4103/1673-5374.139474.

2. Duarte E.P., Curcio M., Canzoniero L.M., Duarte C.B. Neuroprotection by GDNF in the ischemic brain. Growth Factors 2012; 30(4): 242-257, https://doi.org/10.3109/089771 94.2012.691478.

3. Picone R.P., Kendall D.A. Minireview: from the bench, toward the clinic: therapeutic opportunities for cannabinoid receptor modulation. Mol Endocrinol 2015; 29(6): 801-813, https://doi.org/10.1210/me.2015-1062.

4. Schurman L.D., Lichtman A.H. Endocannabinoids: a promising impact for traumatic brain injury. Front Pharmacol 2017; 8: 69, https://doi.org/10.3389/fphar.2017.00069.

5. Pertwee R.G. Cannabinoid pharmacology: the first 66 years. Br J Pharmacol 2006; 147(S1): S163-S171, https://doi. org/10.1038/sj.bjp.0706406.

6. Fernández-Ruiz J., Moro M.A., Martínez-Orgado J. Cannabinoids in neurodegenerative disorders and stroke/ brain trauma: from preclinical models to clinical applications. Neurotherapeutics 2015; 12(4): 793-806, https://doi. org/10.1007/s13311-015-0381-7.

7. Pertwee R.G., Howlett A.C., Abood M.E., Alexander S.P., Di Marzo V., Elphick M.R., Greasley P.J., Hansen H.S., Kunos G., Mackie K., Mechoulam R., Ross R.A. International Union of Basic and Clinical Pharmacology. LXXIX. 
Cannabinoid receptors and their ligands: beyond $\mathrm{CB}_{1}$ and $\mathrm{CB}_{2}$. Pharmacol Rev 2010; 62(4): 588-631, https://doi.org/10.1124/ pr.110.003004.

8. Nagayama T., Sinor A.D., Simon R.P., Chen J., Graham S.H., Jin K., Greenberg D.A. Cannabinoids and neuroprotection in global and focal cerebral ischemia and in neuronal cultures. J Neurosci 1999; 19(8): 2987-2995.

9. Panikashvili D., Shein N.A., Mechoulam R., Trembovler V., Kohen R., Alexandrovich A., Shohami E. The endocannabinoid 2-AG protects the blood-brain barrier after closed head injury and inhibits mRNA expression of proinflammatory cytokines. Neurobiol Dis 2006; 22(2): 257264, https://doi.org/10.1016/j.nbd.2005.11.004.

10. Shohami E., Cohen-Yeshurun A., Magid L., Algali M., Mechoulam R. Endocannabinoids and traumatic brain injury. $\mathrm{Br}$ J Pharmacol 2011; 163(7): 1402-1410, https://doi.org/10.1111/ j.1476-5381.2011.01343.x.

11. Koch M., Kreutz S., Böttger C., Benz A., Maronde E., Ghadban C., Korf H.W., Dehghani F. Palmitoylethanolamide protects dentate gyrus granule cells via peroxisome proliferator-activated receptor-alpha. Neurotox Res 2011; 19(2): 330-340, https://doi.org/10.1007/s12640-010-9166-2.

12. Pazos M.R., Mohammed N., Lafuente H., Santos M., Martínez-Pinilla E., Moreno E., Valdizan E., Romero J., Pazos A., Franco R., Hillard C.J., Alvarez F.J., MartínezOrgado J. Mechanisms of cannabidiol neuroprotection in hypoxic-ischemic newborn pigs: role of $5 \mathrm{HT}(1 \mathrm{~A})$ and $\mathrm{CB}_{2}$ receptors. Neuropharmacology 2013; 71: 282-291, https://doi. org/10.1016/j.neuropharm.2013.03.027.

13. Rosenberg E.C., Patra P.H., Whalley B.J. Therapeutic effects of cannabinoids in animal models of seizures, epilepsy, epileptogenesis, and epilepsy-related neuroprotection. Epilepsy Behav 2017; 70(Pt B): 319-327, https://doi. org/10.1016/j.yebeh.2016.11.006.

14. Mori M.A., Meyer E., Soares L.M., Milani H., Guimarães F.S., de Oliveira R.M. Cannabidiol reduces neuroinflammation and promotes neuroplasticity and functional recovery after brain ischemia. Prog Neuropsychopharmacol Biol Psychiatry 2017; 75: 94-105, https://doi.org/10.1016/j. pnpbp.2016.11.005.

15. Pihlaja R., Takkinen J., Eskola O., Vasara J., LópezPicón F.R., Haaparanta-Solin M., Rinne J.O. Monoacylglycerol lipase inhibitor JZL184 reduces neuroinflammatory response in APdE9 mice and in adult mouse glial cells. J Neuroinflammation 2015; 12: 81, https://doi.org/10.1186/ s12974-015-0305-9.

16. Carloni S., Alonso-Alconada D., Girelli S., Duranti A., Tontini A., Piomelli D., Hilario E., Alvarez A., Balduini W. Pretreatment with the monoacylglycerol lipase inhibitor URB602 protects from the long-term consequences of neonatal hypoxic-ischemic brain injury in rats. Pediatr Res 2012; 72(4): 400-406, https://doi.org/10.1038/pr.2012.91.

17. Valdeolivas S., Pazos M.R., Bisogno T., Piscitelli F., lannotti F.A., Allarà M., Sagredo O., Di Marzo V., FernándezRuiz J. The inhibition of 2-arachidonoyl-glycerol (2-AG) biosynthesis, rather than enhancing striatal damage, protects striatal neurons from malonate-induced death: a potential role of cyclooxygenase-2-dependent metabolism of 2-AG. Cell Death Dis 2013; 4(10): e862, https://doi.org/10.1038/ cddis.2013.387.

18. Celorrio M., Fernández-Suárez D., Rojo-Bustamante E., Echeverry-Alzate V., Ramírez M.J., Hillard C.J., LópezMoreno J.A., Maldonado R., Oyarzábal J., Franco R.,
Aymerich M.S. Fatty acid amide hydrolase inhibition for the symptomatic relief of Parkinson's disease. Brain Behav Immun 2016; 57: 94-105, https://doi.org/10.1016/j.bbi.2016.06.010.

19. Tchantchou F., Tucker L.B., Fu A.H., Bluett R.J., McCabe J.T., Patel S., Zhang Y. The fatty acid amide hydrolase inhibitor PF-3845 promotes neuronal survival, attenuates inflammation and improves functional recovery in mice with traumatic brain injury. Neuropharmacology 2014; 85: 427-39, https://doi.org/10.1016/j.neuropharm.2014.06.006.

20. Su S.H., Wang Y.Q., Wu Y.F., Wang D.P., Lin Q., Hai J. Cannabinoid receptor agonist WIN55,212-2 and fatty acid amide hydrolase inhibitor URB597 may protect against cognitive impairment in rats of chronic cerebral hypoperfusion via PI3K/AKT signaling. Behav Brain Res 2016; 313: 334-344, https://doi.org/10.1016/j.bbr.2016.07.009.

21. England T.J., Hind W.H., Rasid N.A., O'Sullivan S.E. Cannabinoids in experimental stroke: a systematic review and meta-analysis. J Cereb Blood Flow Metab 2015; 35(3): 348358, https://doi.org/10.1038/jcbfm.2014.218.

22. Hind W.H., England T.J., O'Sullivan S.E. Cannabidiol protects an in vitro model of the blood-brain barrier from oxygen-glucose deprivation via PPARY and 5-HT1A receptors. Br J Pharmacol 2016; 173(5): 815-825, https://doi.org/10.1111/ bph.13368.

23. Mukhina I.V., Kazantsev V.B., Khaspeckov L.G., Zakharov Yu.N., Vedunova M.V., Mitroshina E.V., Korotchenko S.A., Koryagina E.A. Multielectrode matrices new possibilities in investigation of the neuronal network plasticity. Sovremennye tehnologii v medicine 2009; 1: 8-15

24. Vedunova M.V., Mishchenko T.A., Mitroshina E.V., Mukhina I.V. TrkB-mediated neuroprotective and antihypoxic properties of brain-derived neurotrophic factor. Oxid Med Cell Longev 2015; 2015: 453901, https://doi. org/10.1155/2015/453901.

25. Paredes M., Etzler J.C., Watts L.T., Zheng W., Lechleiter J.D. Chemical calcium indicators. Methods 2008; 46(3): 143-151, https://doi.org/10.1016/j.ymeth.2008.09.025.

26. Zakharov Yu.N., Korotchenko S.A., Kalintseva Ya.I., Potanina A.V., Mitroshina E.V., Vedunova M.V., Mukhina I.V. Fluorescence analysis of the metabolic activity patterns of a neuronal-glial network. Journal of Optical Technology 2012; 79(6): 348-351, https://doi.org/10.1364/jot.79.000348.

27. Rosi N.L., Giljohann D.A., Thaxton C.S., LyttonJean A.K., Han M.S., Mirkin C.A. Oligonucleotide-modified gold nanoparticles for intracellular gene regulation. Science 2006; 12(5776): 1027-1030, https://doi.org/10.1126/science. 1125559.

28. Yuste R. From the neuron doctrine to neural networks. Nat Rev Neurosci 2015; 16(8): 487-497, https://doi. org/10.1038/nrn3962.

29. Grabiec U., Koch M., Kallendrusch S., Kraft R., Hill K., Merkwitz C., Ghadban C., Lutz B., Straiker A., Dehghani $\mathrm{F}$. The endocannabinoid $\mathrm{N}$-arachidonoyldopamine (NADA) exerts neuroprotective effects after excitotoxic neuronal damage via cannabinoid receptor $1\left(\mathrm{CB}_{1}\right)$. Neuropharmacology 2012; 62(4): 1797-1807, https://doi. org/10.1016/j.neuropharm.2011.11.023.

30. Panikashvili D., Mechoulam R., Beni S.M., Alexandrovich A., Shohami E. $\mathrm{CB}_{1}$ cannabinoid receptors are involved in neuroprotection via NF-kB inhibition. J Cereb Blood Flow Metab 2005; 25(4): 477-484, https://doi.org/10.1038/ sj.jcbfm. 9600047 .

31. Marsicano G., Moosmann B., Hermann H., Lutz B., 
Behl C. Neuroprotective properties of cannabinoids against oxidative stress: role of the cannabinoid receptor $\mathrm{CB}_{1}$. J Neurochem 2002; 80(3): 448-456, https://doi.org/10.1046/ j.0022-3042.2001.00716.x.

32. Ma L., Jia J., Niu W., Jiang T., Zhai Q., Yang L., Bai F., Wang Q., Xiong L. Mitochondrial CB1 receptor is involved in ACEA-induced protective effects on neurons and mitochondrial functions. Sci Rep 2015; 5(1): 12440, https://doi.org/10.1038/ srep12440.

33. Xu C., Hermes D.J., Nwanguma B., Jacobs I.R., Mackie K., Mukhopadhyay S., Lichtman A.H., IgnatowskaJankowska B., Fitting S. Endocannabinoids exert $\mathrm{CB}_{1}$ receptormediated neuroprotective effects in models of neuronal damage induced by HIV-1 Tat protein. Mol Cell Neurosci 2017; 83: 92-102, https://doi.org/10.1016/j.mcn.2017.07.003.

34. Zhuang Q., Dai C., Yang L., Wen H., Wang $H_{\text {., }}$ Jiang $\mathrm{X}$., Zhang $\mathrm{Y}$. Stimulated $\mathrm{CB}_{1}$ cannabinoid receptor inducing ischemic tolerance and protecting neuron from cerebral ischemia. Cent Nerv Syst Agents Med Chem 2017; 17(2): 141-150, https://doi.org/10.2174/187152491666616050 4104624.

35. Smith T.G., Roblins P.A., Ratelife P.J. The human side of hypoxia-inducible factor. Br J Haematol 2008; 141(3): 325334, https://doi.org/10.1111/j.1365-2141.2008.07029.x.

36. Semenza G.L. Hydroxylation of HIF-1: oxygen sensing at the molecular level. Physiology (Bethesda) 2004; 19(4): 176-182, https://doi.org/10.1152/physiol.00001.2004.

37. Semenza G.L. Regulation of physiological responses to continuous and intermittent hypoxia by hypoxia-inducible factor 1. Exp Physiol 2006; 91(5): 803-806, https://doi. org/10.1113/expphysiol.2006.033498.

38. Singh N., Sharma G., Mishra V., Raghubir R. Hypoxia inducible factor- 1 : its potential role in cerebral ischemia. Cell Mol Neurobiol 2012; 32(4): 491-507, https://doi.org/10.1007/ s10571-012-9803-9.

39. Soler-Torronteras R., Lara-Chica M., García V., Calzado M.A., Muñoz E. Hypoximimetic activity of $\mathrm{N}$-acyldopamines. $\mathrm{N}$-arachidonoyl-dopamine stabilizes HIF-1a protein through a SIAH2-dependent pathway. Biochim Biophys Acta 2014; 1843(11): 2730-2743, https://doi.org/10.1016/j. bbamcr.2014.07.005.

40. Abán C., Martinez N., Carou C., Albamonte I., Toro A., Seyahian A., Franchi A., Leguizamón G., Trigubo D.,
Damiano A., Farina M. Endocannabinoids participate in placental apoptosis induced by hypoxia inducible factor-1. Apoptosis 2016; 21(10): 1094-1105, https://doi.org/10.1007/ s10495-016-1274-X.

41. Adamcio B., Sperling S., Hagemeyer N., Walkinshaw G., Ehrenreich H. Hypoxia inducible factor stabilization leads to lasting improvement of hippocampal memory in healthy mice. Behav Brain Res 2010; 208(1): 80 44, https://doi.org/10.1016/j.bbr.2009.11.010.

42. Liu X.L., Lu J., Xing J. Stabilization of HIF-1a modulates VEGF and Caspase- 3 in the hippocampus of rats following transient global ischemia induced by asphyxial cardiac arrest. Life Sci 2016; 151: 243-249, https://doi.org/10.1016/j. Ifs.2016.03.005.

43. Zhu T., Zhan L., Liang D., Hu J., Lu Z., Zhu X., Sun W., Liu L., Xu E. Hypoxia-inducible factor $1 \alpha$ mediates neuroprotection of hypoxic postconditioning against global cerebral ischemia. J Neuropathol Exp Neurol 2014; 73(10): 975-986, https://doi.org/10.1097/nen.0000000000000118.

44. Reischl S., Li L., Walkinshaw G., Flippin L.A., Marti H.H., Kunze R. Inhibition of HIF prolyl-4-hydroxylases by FG-4497 reduces brain tissue injury and edema formation during ischemic stroke. PLoS One 2014; 9(1): e84767, https:// doi.org/10.1371/journal.pone.0084767.

45. Yang Y., Ju J., Deng M., Wang J., Liu H., Xiong L., Zhang J. Hypoxia inducible factor $1 \alpha$ promotes endogenous adaptive response in rat model of chronic cerebral hypoperfusion. Int J Mol Sci 2017; 18(1): 3, https://doi. org/10.3390/ijms18010003.

46. Yan J., Huang Y., Lu Y., Chen J., Jiang H. Repeated administration of ketamine can induce hippocampal neurodegeneration and long-term cognitive impairment via the ROS/HIF-1a pathway in developing rats. Cell Physiol Biochem 2014; 33(6): 1715-1732, https://doi.org/10.1159/000362953.

47. Yin R., Yuan L., Ping L., $\mathrm{Hu}$ L. Neonatal bronchopulmonary dysplasia increases neuronal apoptosis in the hippocampus through the HIF-1 $1 \alpha$ and p53 pathways. Respir Physiol Neurobiol 2016; 220: 81-87, https://doi. org/10.1016/j.resp.2015.09.011.

48. Li A., Sun X., Ni Y., Chen X., Guo A. HIF-1a involves in neuronal apoptosis after traumatic brain injury in adult rats. J Mol Neurosci 2013; 51(3): 1052-1062, https://doi. org/10.1007/s12031-013-0084-7. 